\title{
Sexual Communication of Parents and Children: The Theory of Reasoned Action and Planned Behavior
}

\author{
María Aracely Márquez Vega ${ }^{1 *}$, Raquel Alicia Benavides Torres ${ }^{2}$ and Esther C Gallegos \\ Cabriales $^{3}$
}

${ }^{1}$ Dra. Universidad Autónoma de Nuevo León, Facultad de Enfermería y Centro de Investigación en Ciencias de la Salud, UANL. Monterrey, N. L. México

${ }^{2}$ PhD. Universidad Autónoma de Nuevo León, Facultad de Enfermería y Centro de Investigación en Ciencias de la Salud, UANL. Monterrey, N. L. México.

${ }^{3}$ PhD. Universidad Autónoma de Nuevo León, Facultad de Enfermería. Monterrey, N. L. México

*Corresponding author: María Aracely Márquez Vega, Universidad Autónoma de Nuevo León, Facultad de Enfermería y Centro de Investigación en Ciencias de la Salud, UANL, Gonzalitos 1500 Norte. Monterrey, Nuevo León. México. CP. 64460

\section{ARTICLE INFO}

Received: 蔧 June 22, 2019

Published: 蔧 July 03, 2019

Citation: María Aracely M V, Raquel Alicia Benavides T, E C Gallegos Cabriales. Sexual Communication of Parents and Children: The Theory of Reasoned Action and Planned Behavior. Biomed J Sci \& Tech Res 19(3)-2019. BJSTR. MS.ID.003290.

Keywords: Sexual Communication; Theory of Reasoned Action; Planned Behavior; Parents and Children

\begin{abstract}
The objective of this revision is to explain how sexual communication of parents and children occurs using the Theory of Reasoned Action (TRA) and Planned Behavior. The TRA has proven validity and usefulness to explain health behaviors. The theory states that behaviors are under the control of the individual with the person being a rational being who processes information using it in a structured manner with the aim of evaluating and making decisions. Behavior is determined by a logical thinking process called intention. The intention of the individual of carrying out a particular behavior is achieved as a result of the interrelation between behavioral and normative beliefs. Ajzen and Fishbein (1988) expanded the concepts and relationships of TRA and proposed the Theory of Planned Behavior (TPB). In this extension, another belief is introduced, behavioral control, which is described as the perception of factors that can facilitate or impede the performance of a behavior. Because of the aforementioned, this theory is considered pertinent for explaining sexual communication of parents and adolescent children.
\end{abstract}

\section{The Theory of Reasoned Action and Planned Behavior}

The Theory of Reasoned Action (TRA) has proven its validity and usefulness to explain health behaviors; it has also been used to substantiate interventions that modify health behaviors [1]. This theory is applicable to explain how sexual communication occurs between parents and children. The TRA of Fishbein and Ajzen [2] states that behaviors are under the control of the individual because humans are rational beings that process information, using it in a structured manner with the aim of evaluating and making decisions. In other words, behavior is determined by a process of logical thought known as intention. Likewise, the individual's intention to perform a specific behavior is achieved as a result of the interaction between behavioral and normative beliefs. Therefore, a brief description of how beliefs are formed is presented.

\section{Beliefs}

Beliefs refer to subjective judgement of the relationship between the object of belief, other objects, values, concepts or attributes that make people understand themselves and the environment that surrounds them. The source of information for this relationship is direct observation. These direct experiences with the object give, as a result, the creation of descriptive beliefs. Other beliefs, called inferential beliefs, which go beyond a direct observable relationship, also exist. The difference between these two types of beliefs is that the former has to do with the acquisition of new information and the latter with the processing of information. Therefore, an individual forms his or her beliefs of an object from direct observation and the information received from external sources. In this way, the 
human being is conceived as a rational being that uses available information to emit judgements that lead to decision making. These personal beliefs serve as baseline information that determines their attitudes, intentions, and behaviors.

\section{Attitudes}

According to the aforementioned, the attitude of the individual towards an object is based on their behavioral beliefs, which are unique and refer to the subjective probability that the behavior will produce a favorable or unfavorable result. The attitude of a person influences the way an action is performed since it is related to the belief that a certain behavior will lead to certain consequences. According to this, attitude is seen as the greatest determinant of the intention to perform said behavior. It can be said that the parent's belief regarding a favorable or unfavorable result in the communication of sexual topics with their adolescent children, such as the prevention of unwanted pregnancies, STDs and HIV/ AIDS, will increase or decrease the intention of speaking with their children about contraceptive methods or condoms.

\section{Subjective Norm}

Another relevant belief for a behavioral intention to occur is the normative belief, which refers to the person's perception regarding the approval of important referents (other individuals or groups) about a certain behavior; these beliefs are of a social nature. The normative component requires establishing a relationship between the information base and its specific components and that its effects be examined. According to this, the individual may or may not be motivated if they receive normative pressure from a referent. The interrelation between normative beliefs and this motivation is called a subjective norm. In other words, parents will have greater communication regarding sexual topics with their adolescent children if they believe that others, such as the family, their children or the church, approve this. According to this, intention has two precursors that explain it: one that is individual, which is the attitude towards behavior, and another, which is social, called the social norm $[3,4]$.

\section{Perceived Behavioral Control}

Ajzen and Fishbein [3] expanded the previously mentioned concepts and relationships of the Theory of Reasoned Action and proposed the Theory of Planned Behavior. In this extension, another belief is introduced, the belief of control, which is described as the perception of factors that can facilitate or impede the performance of a behavior. The authors assumed that these beliefs, in combination with the power perceived over factors to control, determine the perceived control of behavior. In other words, the power that the person perceives over factors that impede or facilitate carrying out a behavior contributes to the perception of behavioral control. It is important to mention that the foregoing should be in direct relation to the subjective probability that the control factor is present. Therefore, perceived behavioral control is the person's perception of his or her ability to carry out a determined behavior. In contrast to the other two beliefs, only the perceived behavioral control can directly or indirectly predict the intention and/or behavior. Based on this, it is said that parents will talk with their children about sex issues if they believe they have the necessary capacity to do so.

\section{Internal Factors}

Ajzen [3] analyzed several factors that can influence the degree of control that a person has over a given behavior. He mentions that there are internal factors such as information, abilities, capacities, and emotions. Internal factors are elements that depend on the individual and that can facilitate or hinder control over certain behaviors. The internal factors that can influence communication between parents and children are the knowledge of sexual topics and the comfort to communicate them. These factors are described below. Achterbergh and Vriens [5] state that knowledge is a dynamic, conscious and fundamental process that precedes the individual's decision making and behavior. Knowledge allows articulating the possible course of actions, judging if the course of these will lead to the planned result, and using these judgments to select the actions that will be executed. Likewise, Givaudan, Vijver, and Poortinga [6] define knowledge as the information that increases the range of alternatives of courses of action that can be considered by an individual in a particular situation.

Knowledge is directly related to the perceived control of behavior. Studies indicate that parents that perceive greater ability and capacity to talk with their children about sex topics are those that consider that they have the necessary knowledge to communicate these topics $[7,8]$. Therefore, the knowledge of sex topics is the information that a parent has about the methods of transmission of STD/HIV---AIDS, their prevention and that of unwanted pregnancies. Likewise, comfort refers to a comfortable or pleasant feeling that produces wellbeing. A relationship between this variable and perceived behavioral control and knowledge has been found. Research studies have found that parents of adolescents who perceive that they have the necessary knowledge report that they feel more comfortable speaking about sex $[9,10]$. Villarruel et al. [10] found that there is a relation between the belief of control and the parent's comfort to communicate about sex. The comfort to communicate sex matters is conceptualized as the comfortable feeling that the parent perceives when sharing information with their adolescent child about topics related to sexuality such as pregnancies at an early age, STD, and HIV/AIDS.

\section{Individual Variables}

Additionally, TRA establishes that any individual variable, such as sociodemographic or personal characteristics (for example, sex, religion, education, personal stimulus, etc.) can influence intention through attitudes, subjective norms, and perceived behavioral control. However, there are studies that show that sex and education are directly related to communication of sex topics $[8,11,12]$, making it possible to state that individual variables, such as sex and education, are related to attitudes, the subjective norm, perceived behavioral control, and communication about sex 
topics; in turn, these individual variables indirectly influence the intentions of sexual communication.

\section{Intention}

Intentional behavior is composed of four elements: the behavior, the object that the behavior is directed at, the situation in which the behavior is carried out (place), and the time in which the behavior is performed [4]; all these elements are a function of the behavior itself. In consequence, the most specific level of intentions is that in which the person proposes carrying out an action regarding a given object at a specific moment and situation. Therefore, intention is considered the predictor closest to behavior and it is determined by the beliefs of individuals. An individual will have the intention to perform a given behavior when he or she has a positive attitude towards their own performance, when he or she believes that his or her significant social referents think that he or she should carry it out, and when he or she considers that he or she has the skills to perform it [13]. The parent's intention to communicate with their adolescent children about sex is determined by attitudes, subjective norm, and perceived behavioral control; therefore, if the parents have the intention of communicating about sex, it is more probable that they will.

\section{Behavior}

Behavior is defined as the observable manifestation of specific behavior and it is determined by the intention to carry out said behavior. The expected behavior of parents is sexual communication with their adolescent children. According to King [14], communication is the means by which information is transmitted in specific situations to identify interests or problems that will allow adequate decision making. Communication of sex topics is conceptualized as the means by which the father or mother shares information with their adolescent child about how to protect themselves from early pregnancy, STD, and HIV/AIDS. The relationships of these concepts are presented in (Figure 1).

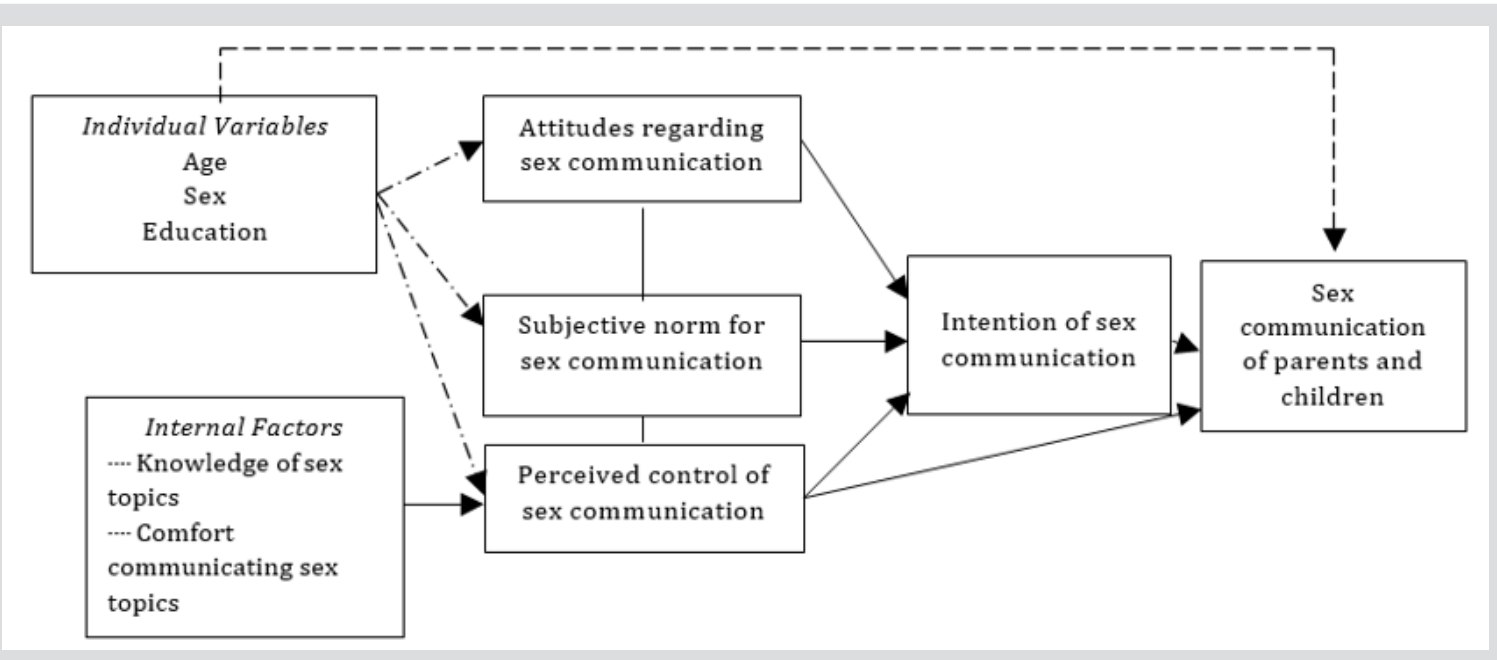

Figure 1: Diagram of the relationship of Theory of Planned Behavior (TPB) concepts for sexual communication of parents and children.

\section{References}

1. Ajzen I (1991) The theory of planned behavior. Organizational Behavior and Human Decision Processes 50(2): 179-211.

2. Ajzen I, Fishbein M (1980) Understanding attitudes and predicting social behavior. Londres: Prentice Hall International.

3. Ajzen I, Fishbein M (1988) From intentions to actions. En I Ajzen (edn.). Attitudes, personality and behavior. Chicago: The Dorsey Press.

4. Fishbein M, Ajzen I (1975) Belief, attitude, intention and behavior: An introduction to theory and research. Massachusetts: Addison Wesley.

5. Achterbergh, Jan Vriens, Dirk (2002) Managing viable knowledge. Systems Research and Behavioral Science 19(3): 223-241.

6. Givaudan M, Poortinga YH, Van de Vijver F (2005) Identifying precursors of safer sex practices in Mexican adolescents with and without sexual experience: An exploratory model. Journal of Applied Social Psychology 35(5): 1089-1109.

7. Dilorio C, McCarty F, Denzmore P (2006) An exploration of social cognitive theory mediators of father son communication about sex. Journal of Pediatric Psychology 31(9): 917-927.

8. Lehr ST, Dilorio C, Dudley WN, Lipana JA (2000) The relationship between parent adolescent communication and safer sex behaviors in college students. Journal of family nursing $6: 1-16$.
9. Miller KS, Levin ML, Whitaker DJ, Xu X (1998) Patterns of condom use among adolescents: The impact of mother adolescent communication. American Journal of Public Health 88(10): 1542-1544.

10. Villarruel AM, Loveland C, Gallegos EC, Ronis DL, Zhou Y (2008) A parent adolescent intervention to increase sexual risk Communications: results of a randomized controlled trial. AIDS Education and Prevention, 20(5): 371-383.

11. Márquez MA, Duran MR (2007) Autoeficacia en comunicación de padres a hijos sobre temas de sexo. Desarrollo Científico de Enfermería 15: 1215.

12. Somers Ch L, Paulson SE (2000) Students' perception of parent adolescent closeness and communication about sexuality: relation with sexual knowledge, attitudes and behaviours. Journal of Adolescent 23(5): 629-644.

13. Fishbein M (1990) AIDS and behavior change: An analysis based on the theory of reasoned action. Interamerican Journal of Psychology 24(1): 37-55.

14. King IM (1992) Enfermería como profesión. Filosofía, principios y objetivos. Ed Limusa. 


\section{ISSN: 2574-1241}

DOI: 10.26717/BJSTR.2019.19.003290

María Aracely Márquez Vega. Biomed J Sci \& Tech Res

(c) (P) This work is licensed under Creative

Submission Link: https://biomedres.us/submit-manuscript.php

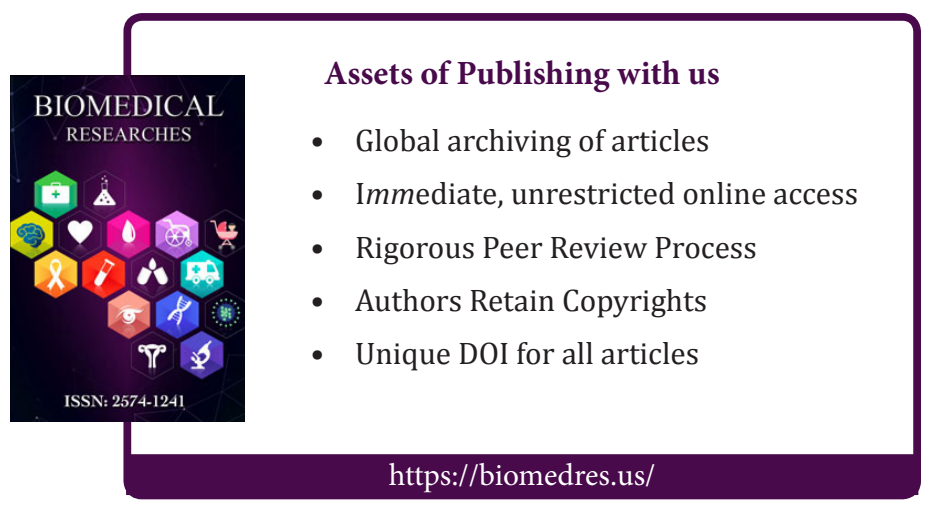

